\section{Effects of conceptual change pedagogy on achievement by high ability integrated science students on energy concepts}

Igwebuike, Thomas B. $\bowtie$

College of Education, Warri, Nigeria (dadaigwebuike@yahoo.com)

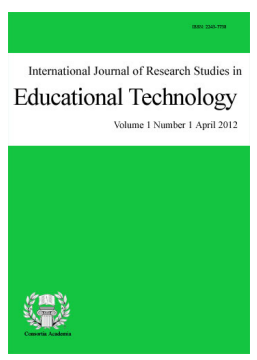

ISSN: $2243-7738$ Online ISSN: 2243-7746

OPEN ACCESS

\title{
Abstract
}

Strands of evidence from research on science teaching support the use of conceptual change pedagogy for teaching science at the primary and secondary school levels (grades 1-12). This model emphasizes the determination of students' alternative conceptions and organizing a conducive learning environment for negotiation between the students and their teachers. Meaningful learning of science takes place within this type of learning environment. Despite this, there is the need to investigate the efficacy of this model for each of the levels of the various characteristics of students. This study, therefore, sought to find out if high achievers in integrated science taught using conceptual change pedagogy will achieve significantly better than their counterparts taught through the expository strategy. A total of 100 (54 boys, 46 girls) junior secondary school (grade 8) high achievers took part in this study. Using a non-equivalent control group design, the experimental group was taught energy concepts using conceptual change pedagogy while a second group was taught using expository method. No statistically significant difference was found between the two groups in cognitive achievement. But a significant difference was found in affective achievement between the two groups. The implications of the findings for integrated science teaching and further research are drawn.

Keywords: integrated science; conceptual change pedagogy; constructivism; alternative conceptions; high achievers 


\section{Effects of conceptual change pedagogy on achievement by high ability integrated science students on energy concepts}

\section{Introduction}

One of the primary objectives of integrated science teaching is that students learn scientific concepts in a meaningful manner. Meaningful learning, as conceptualized by Ausubel (1963), results when an individual consciously and carefully relates new knowledge to relevant concepts or propositions possessed by him prior to the instruction. Such concepts are developed by the students from the cultural knowledge, beliefs, attitudes and values, and the prevailing theoretical paradigms in their environments. All these constitute what Igwebuike (1988) refers to as conceptual ecology. Head (1986) identifies the origin of the concepts by exposing five possibilities. These are: everyday experience and observation, confusion about analogies, use of metaphors, peer culture, and innate origin.

A. Everyday Experience and Observation- Students develop a number of working theories as explanations of their experience and observation while interacting with physical objects like metals, plastic and glass materials, rubber, discarded batteries etc, in their environments.

B. Confusion about Analogies- Students often encounters confusion when they try to interpret analogies that are common in their conceptual ecology.

C. Use of metaphors- Their conceptual ecology is laden with metaphors which are compressed comparisons and which may not be as precise as scientific descriptions and explanation.

D. Peer Culture- Students interact informally with peer members and within this may share ideas, descriptions and explanations from their conceptual ecology which may be at dissonance with scientific tradition.

E. Innate Origin- Students may be genetically programmed to manipulate the environment in ways different from those accepted by the scientific tradition.

Curricular Science in Nigeria and indeed Africa is based on Western Scientific Tradition. For instance, Cobern $(1991,1996)$ argues that the West is the historic home of modern science, modern because of a hypothetical- deductive, experimental approach to science. He concludes by saying that it follows then that science education is an aspect of culture and consequently it is appropriate to speak of Western science education. Nigerian culture is Non-Western and by implication, the conceptual ecology is quite different from that in the Western cultures. The differences in the two types of conceptual ecology have conspired with transfer of Western science to schools in Africa, without determining its relevance, to make learning of science in the schools very difficult. The literature is replete with support for this observation (Odhiambo, 1972; Ogunniyi, 1984, 1988; Lewin, 1990; Okebukola \& Jegede, 1990; Kyle, 1993). For instance, Lewin (1990) observes that many more children in developing countries study science than before but that available evidence "suggests that the great majority do not master more than a small proportion of the goals set for them" (p.1). He also says that much work has to be done by science educators by way of developing "ways of representing science that are not foreign, expert and culturally unsympathetic" (p.2).

While issues can still be taken with the cultural relevance of Western Science, a suggestion has been made (Cobern, 1996) that we turn our gaze to a view of learning that is 'transferable across, and appropriate for, different cultural environments" (p.6). This view of learning is constructivism. The view developed much after empiricist view of science. Constructivist approach to instruction and learning is an off-shoot of epistemology of the interpretative or Verstehen tradition which emphasizes meaning as constructed by individuals in their 
attempts to make sense of their world (Gilbert \& Watts, 1983; Driver \& Oldham, 1986). The other tradition, the Erklaren is realist in outlook, showing conformity with an empiricist- inductivist view of knowledge, with a belief in the value of a reductionist approach to phenomena and the use of replicable experimental methods in the search for causal mechanisms (Gilbert \& Watts, 1983). Constructivist epistemology acknowledges that learners actively generate meaning from experience and develop their personal constructs or mini theories.

Specifically, constructivist views about learning, as presented by Driver and Oldham (1986) are:

A. Individuals are purposive- Learning does not take place by the learner responding in a passive way to the environment;

B. Prior knowledge matters a lot- Learning depends not on the learning environment per se, but on what knowledge the learner brings to the learning situation;

C. Knowledge is constructed by individuals through social interactions and experience with physical environment, personal knowledge is constructed so as to "fit" with experiences in a coherent way;

D. Meaningful learning involves the construction of links with prior knowledge;

E. The construction of meaning is an active process in which the learner generates possible hypothetical links and checks them for "fit" in the situation.

F. Learning science involves conceptual change; it involves not only adding and extending one's conceptual structure but may involve radically reorganizing it.

From the foregoing, a major tenet of constructivist epistemology is that the individual's prior knowledge, which is referred to as alternative conception, following Abimbola (1988) exposition, is very crucial, not just tangential, to meaningful learning. Construction of meaning or sense-making is carried out by the individual on the basis of his alternative conceptions relative to the subject matter of study. The work of the teacher is not authoritarian dissemination of subject matter but organization of conducive learning environment for negotiation which enables the teacher and the students to arrive at some consensus of meaning (Jegede \& Taylor, 1998).

A Typical sequence of instructional events using this epistemology is given as follows:

A. Determine students' alternative conceptions using interview-about-instances (as in this study) or any other approach.

B. Catalogue the alternative conceptions according to types.

C. Determine the conflict level between alternative conceptions and scientific conceptions of study.

D. Present scientific conceptions to be studied.

E. Conflict resolution through negotiations which will lead to consensus building.

F. Testing the fruitfulness, intelligibility, etc, (Strike \& Posner, 1985) of the two sets of conceptions (this is also an integral part of item $\mathrm{E}$ ).

G. Discussion of areas of application of the scientific conceptions developed.

H. Determination of students' affective state after they have discarded their dissonant alternative conceptions.

Several strands of research evidence converge to attest to the efficacy of conceptual change pedagogy which is premised on constructivist epistemology and which has been elaborated on earlier (Snivey, 1985; Rowell \& Dawson, 1985; Zietsman \& Hewson, 1986; Trumper, 1990, 1991; Asim, 1999; Bajah \& Asim, 2000, Ndioho, 
2007; Igwebuike, 2000). These studies have suggested that the use of this pedagogy has led to meaningful learning of science concepts by students. But some studies (Chang, 2000; Chang \& Bell, 2002, Igwebuike \& Oriaifo, 2009) provide lines of evidence which suggest that students in conceptual change classes were found to have similar academic achievement with their peers in the traditional classes. By implication, a consensus of conclusions, though not necessarily a desideratum has not been reached.

One of the major themes in the Nigerian Integrated Science Project is energy. Nigeria is one of the oil mineral producing countries and people discuss oil mineral, energy and related concepts, very often, in ways that are at variance with the subject matter of science. This means that students' conceptual ecology is laden with ideas that can easily make them to develop dissonant alternative conceptions. Yet not much is known about the influence of the conceptual ecology on the learning of energy related concepts in science. Attempts have been made to explore this type of influence on learning of energy concepts in some cultures based on Western Scientific Tradition. For instance, Duit $(1981,1984)$ and Solomon $(1983 a, 1983 b)$ have expressed the difficulty of teaching energy concepts to students in Germany and the United Kingdom respectively. Bell (2005) acknowledges the difficulties in teaching and learning energy at the junior secondary school level in New Zealand.

It can be conjectured that high ability integrated science students will be more receptive to conceptual change pedagogy than the low ability students because it involves the extraction of their alternative conceptions, an exercise which may not be easy with low ability students. Secondly, assessment of the plausibility, intelligibility and fruitfulness of the scientific conception of study by the students in preparation for conceptual change as suggested by Strike and Posner (1985), may be more intellectually demanding on the low ability students. But not much can be known from review of the literature on this phenomenon. This conjecture was tested in this study. It is hoped that the findings will provide some enlightenment as regards the search for ways of bringing about meaningful learning of energy concepts by students of different ability levels. Specifically, the following null hypotheses were tested:

A. There is no significant difference in cognitive achievement on energy concepts between high ability junior secondary school students (grade 8) taught using conceptual change pedagogy and their counterparts taught using traditional expository strategy.

B. There is no significant difference in affective achievement between high ability junior secondary students (grade 8) taught using conceptual change pedagogy and their counterparts taught using traditional expository strategy.

\section{Method}

\subsection{Subjects}

One hundred junior secondary school students (grade 8) of Delta Career Secondary School, Warri, Nigeria and Step Forward Secondary School, Warri, Nigeria were involved in this study. The subjects ( 54 boys, 46 girls) ranged in age from 12 years 3 months to 16 years with a mean age of 14 years 5 months and were the high ability group (upper half) from a median split made after arranging all the students in the classes according to their scores on integrated science terminal examination. All the subjects took integrated science as one of their subjects preparatory to the junior secondary school certificate examinations.

\subsection{Instruments}

Three instruments were used in this study. They are (i) Cognitive Achievement Test (ii) Affective Achievement Questionnaire and (iii) Interview-about-instances. The first two provided measures of the two dependent variables while the last was used for obtaining the subjects' alternative conceptions. Cognitive 
Achievement Test was used for measuring cognitive achievement based on energy concepts referenced to the objectives of instruction in this study. The test had 30 multiple test items. Four sub-concepts of energy as demarcated by Learning in Science Project of the University of Waikato, New Zealand were used for developing the lessons. They are:
A. Energy as an invention (6 items).
B. Forms of energy (8 items).
C. Systems undergoing change (8 items).
D. Conservation of energy y (8 items).

Initially the test had 35 items and these were reduced to 30 following recommendations of a panel of 3 experienced integrated science teachers and 2 specialists on measurement and evaluation. Psychometric integrity of the test was determined using a pilot sample of 63 grade 8 students from a junior secondary school not used for the main study in two ways. The first is that the discriminatory power and the difficulty indexes, of the items were determined using suggestions by Mehrens and Lehmann (1975). These measures were found to be within acceptable ranges. Specifically, the range with respect to the difficulty index was established at between 0.28 and 0.75 while the index of discriminatory power was between 0.31 and 0.65 . The second is that the reliability coefficient was determined using Cronbach alpha technique. This exercise yielded a value of 0.75 which was considered reasonable enough for use.

Affective Achievement Questionnaire designed and factorially validated by Afemikhe (1985) was used to measure affective achievement resulting from the use of conceptual change pedagogy. The instrument had 4 sub-scales of self-concept, confidence, attitude and motivation with 12, 3, 8 and 3 items respectively. The reliability coefficients of the items determined using Cronbach alpha were $0.65,0.59,0.46$ and 0.45 respectively. Using test-retest method and a sample of 50 JS II (grade 8) students not included in the main study, a composite reliability coefficient was determined for the instrument. This exercise yielded a value of 0.55 .

Interview-about-instances was developed and popularized by Osborne and Gilbert (1980a, b). Using line drawings on different cards, instances of a concept, in this case, energy, were presented to the subjects who were asked one after the other (during interview sessions), if each card contained an instance of the concept or not. The subjects were requested to give reasons for their responses. They were allowed to ask questions to clarify any ambiguities generated by the exercise or the cards before answering the questions to be posed. From their responses identical conceptions were categorized into alternative conceptions following Gilbert and Watts' (1983) recommendation.

The cards were designed on the basis of the sub-concepts of energy, delineated earlier, which were taught. Assistance of graduates' teachers of physics, biology, integrated science and chemistry was sought while designing the cards. Care was taken to control the number of cards used per sub-concept during the exercise to reduce boredom and fatigue on the part of the students during interview sessions. Content validity of the cards, with respect to the sub-concepts, was ascertained by these graduates in the various areas.

\subsection{Procedure}

A non-equivalent control group design with random assignment of the subjects to experimental and control groups was employed to examine any possible treatment effect due to exposure to conceptual change pedagogy (CCP). Experimental group was taught using the CCP while the control was taught using the expository method (E.M). The two groups shared a common curriculum content-energy which was decomposed into the following:

A. Energy as an invention

B. Forms of energy 
C. Systems undergoing change

D. Conservation of energy

The Cognitive Achievement Test and the Affective Achievement Questionnaire were administered to all the subjects as pre-tests. Interview-about-instances was carried out on 15 randomly selected subjects in the experimental group using the cards with line-drawings of the sub-concepts. From this exercise a catalogue of 17 alternative conceptions was prepared. These were compared with scientific conceptions and used as the basis for organizing conceptual change instructional strategy.

This was followed by eight weeks of instructional treatments based on conceptual change pedagogy. The model and the steps involved have been presented earlier. The researcher administered the treatments' to control the effects of some plausible teacher variables like skills-gap, commitment to the use of conceptual change pedagogy for teaching experimental group, perceptions of, and beliefs about classroom practices, and knowledge of the subject matter of study. Each group was taught for eight weeks with a total of twelve lessons of about 40 minutes per lesson.

One of the steps in conceptual change pedagogy involves the presentation of the relevant alternative conceptions, which have been catalogued, to the experimental group. After this, the relevant scientific conceptions were presented and the subjects in this group were assisted by the researcher/teacher to assess the usefulness and plausibility of their conceptions. Lawson and Thompson (1988) observe that students at the concrete operational level find it difficult to evaluate competing theories. This observation necessitated providing some guides to these subjects, who were also at this level, for analyzing the implications of both their conceptions and scientific conceptions.

Subjects in the control group were not given the interview as was done with the experimental group. They were taught using the expository method. After eight weeks of instruction, the two groups were given the post-tests on cognitive and affective achievements. These tests were administered in the same manner as the pre-test.

\section{Findings}

The students in the experimental and control groups were found to have initial differences in cognitive and affective achievements from the analysis of the pre-tests $\left[\mathrm{t}_{(98)}=4.93, p<0.05\right]$ and $\left[\mathrm{t}_{(98)}=9.72, p<0.05\right]$ respectively. Analysis of covariance (ANCOVA) was used for subsequent analysis because it can adjust for any initial difference in measures of dependent variables.

\section{Table 1}

T-test on experimental and control groups of cognitive achievement on energy concept

\begin{tabular}{lcccc}
\hline \multicolumn{1}{c}{ Items } & $\mathrm{N}$ & Mean & $S D$ & $t$ \\
\hline Experimental & 50 & 4.86 & 1.83 & $4.93 *$ \\
Control & 50 & 3.19 & 1.91 & \\
\hline
\end{tabular}

Note. ${ }^{*} p<0.05$

Table 2

T-test on experimental and control groups of affective achievement on energy concept

\begin{tabular}{llllc}
\hline \multicolumn{1}{c}{ Items } & $\mathrm{N}$ & Mean & $S D$ & $t$ \\
\hline Experimental & 50 & 44.92 & 7.52 & $9.72 *$ \\
Control & 50 & 51.37 & 7.16 & \\
\hline
\end{tabular}

Note. ${ }^{*} p<0.05$ 
Effects of conceptual change pedagogy on achievement by high ability integrated science students

The aim of this study was to determine if instruction using conceptual change pedagogy had any significant effect on cognitive and affective achievement by high achievers in integrated science. The results are presented in the tables that follow.

\section{Table 3}

ANCOVA summary of cognitive achievement post-test scores

\begin{tabular}{|c|c|c|c|c|}
\hline Source of variance & SS & $d f$ & $M S$ & $F$ \\
\hline Covariates & 392.421 & 1 & 392.421 & 24.31 \\
\hline Method & 41.201 & 1 & 41.201 & $2.68 *$ \\
\hline Explained & 433.622 & 2 & 221.567 & 13.92 \\
\hline Residual & 1421.323 & 97 & 15.361 & \\
\hline TOTAL & 1854.945 & 99 & & \\
\hline
\end{tabular}

Note. ${ }^{*} p>0.05$

\section{Table 4}

Corresponding multiple classification analysis

\begin{tabular}{lcccc}
\hline $\begin{array}{l}\text { Grand mean = 17.34 } \\
\text { Variable + Category }\end{array}$ & $\mathrm{N}$ & $\begin{array}{c}\text { Unadjusted } \\
\text { deviation ETA }\end{array}$ & $\begin{array}{c}\text { Adjusted for independents }+ \\
\text { covariance deviation }\end{array}$ & Beta \\
\hline $\begin{array}{l}\text { Method } \\
\text { Conceptual change } \\
\text { pedagogy }\end{array}$ & 50 & -0.04 & -0.06 \\
$\begin{array}{l}\text { Expository method } \\
\quad \text { Multiple R squared }\end{array}$ & 50 & 0.04 & 0.06 & 0.030 \\
$\quad$ Multiple R & & & 0.004 \\
\end{tabular}

The results in Tables 3 and 4 show that method did not have a significant effect $\left[F_{(1,97)}=2.68, p>0.05\right]$. The corresponding multiple classification analysis reveals that high achievers exposed to conceptual change pedagogy had an adjusted cognitive achievement mean score of 17.28 while their counterparts taught by using expository method had an adjusted cognitive achievement mean score of 17.40 . The null hypothesis was therefore not rejected. By implication, conceptual change pedagogy did not improve the achievement in integrated science by experimental group.

With respect to affective achievement, there was significant difference in favor of high achievers in the experimental group $\left[\mathrm{F}_{(1,97)}=27.942, p<0.05\right]$ (Table 5). This group had an adjusted posttest affective achievement mean score of 62.84 while their counter parts taught through expository method recorded an adjusted posttest mean score of 58.54 .

\section{Table 5}

ANCOVA summary of affective achievement post-test scores

\begin{tabular}{|c|c|c|c|c|}
\hline Source of variance & SS & $d f$ & $M S$ & $F$ \\
\hline Covariates & 1563.800 & 1 & 1563.800 & 94.499 \\
\hline Method & 462.400 & 1 & 462.400 & $27.942 * *$ \\
\hline Explained & 2026.200 & 2 & 1013.100 & 61.221 \\
\hline Residual & 1605.190 & 97 & 16.548 & \\
\hline TOTAL & 3631.390 & 99 & 36.681 & \\
\hline
\end{tabular}

Note. ${ }^{* *} p<0.01$ 
Igwebuike, T. B.

Table 6

Corresponding multiple classification analysis

\begin{tabular}{lcccc}
\hline $\begin{array}{c}\text { Grand mean = 17.34 } \\
\text { Variable + Category }\end{array}$ & $\mathrm{N}$ & $\begin{array}{c}\text { Unadjusted } \\
\text { deviation ETA }\end{array}$ & $\begin{array}{c}\text { Adjusted for independents + } \\
\text { covariance deviation }\end{array}$ & Beta \\
\hline $\begin{array}{l}\text { Method } \\
\text { Conceptual change }\end{array}$ & 50 & 2.49 & 2.15 \\
pedagogy & & & & \\
Expository method & 50 & -2.29 & -2.15 & 0.360 \\
$\quad$ Multiple R squared & & 0.38 & 0.558 \\
$\quad$ Multiple R & & & 0.747 \\
\hline
\end{tabular}

The hypothesis of no difference in group means in affective achievement was therefore rejected. By implication, high achievers taught using conceptual change pedagogy had a significantly superior achievement over their counterparts taught using the expository method.

\section{Discussions and conclusions}

The data from this study do not provide support for the potency of the conceptual change pedagogy in bringing about the learning of energy concepts by high achievers in integrated science. The experimental group taught using this pedagogy did not show any superior performance in the cognitive dimension than their counter parts taught through expository method $\left[\mathrm{F}_{(1,97)}=2.68, p>0.05\right]$, as reported in Table III. This is in accord with the findings of previous studies (Chang, 2000; Chang \& Bell, 2002; Igwebuike \& Oriaifo, 2009) but presents a stark contrast to findings in studies by Zietsman and Hewson (1986), Trumper (1990, 1991); Asim (1998); Bajah and Asim (2002); Ndioho (2007).

Conceptual change pedagogy which is rooted in constructivist epistemology has the potency to bring about meaningful learning of science (Benjamin \& Egho, 2008). For instance, it provides a learning environment in which students are actively involved in construction of knowledge when assessing the fruitfulness, plausibility and intelligibility of their alternative conceptions vis a vis the scientific conception of study (Strike and Posner, 1985; Bell, 2005). It also provides an effective social environment for negotiations between students and teachers (Bauersfeld, 1991; McCarty, 1991 Wheatley, 1997; Jegede \& Taylor, 1998) and negotiation allows students to develop reflection and self-control, and allows them to become an integral part of classroom communication (Bauersfeld, 1991). From these features of conceptual change pedagogy, there is the possibility of the individual learners generating their own understanding of the concepts being studied in the class when it is used. But this study presents result which contradicts an expectation based on the foregoing.

Two factors, speculatively, and as argued elsewhere (Igwebuike \& Oriaifor, 2009), have influenced the unexpected result. The first is the novelty provided by this pedagogy. In this type of learning situation, much premium is placed on students' alternative conceptions. The teacher respects these alternative conceptions and opinions during negotiation phase and makes himself a part of the problem-solving group. This type of situation is in stark contrast with the authoritarian dissemination of body of knowledge of science by the teacher which the students are used to. From the students' point of view, seemingly, this type of learning environment would not be for examination or test purposes as the expository strategy. The hunch is that the post-test did not elicit adequate responses from the high achievers taught using conceptual change pedagogy.

The origin of the second factor is the nature of the cognitive post-test used in this study. It consisted of a number of multiple choice items referenced to the four sub-concepts of energy, as mentioned earlier. If interview-about-instances, which is one of the features of the conceptual change pedagogy, was subtly built into the achievement post-test, the results might have been different.

Another somewhat plausible factor is the acknowledged difficulty in teaching and learning energy at the 
junior secondary level (Kirkwood, 1989; Bell, 2005). One of the reasons for this difficulty is the abstract nature of the concept (Bell, 2005). But the content of this concept used for teaching in this study took care of this abstract nature of the concept because it is decomposed into (1) energy as an invention, (2) forms of energy, (3) systems undergoing change, and (4) conservation of energy by the Learning in Science Project of the University of Waikato, New Zealand, besides the difficulty expressed was a common denominator for both the experimental and control groups.

With respect to the affective achievement, the data from the study provide support for the potency of the conceptual change pedagogy. The experimental group taught using this pedagogy was found to achieve significantly better than their control-group counterparts $\left[\mathrm{F}_{(1,97)}=27.942, p<0.05\right]$. This agrees with the findings of Trumper (1990, 1991); Asim (1998); Kim, Fisher, and Fraser, (1999); Bajah and Asim (2000); Ndioho (2007). For instance, Ndioho's (2007) study indicated that conceptual change pedagogy was significantly more effective in teaching genetics to secondary school biology students than conventional lecture method. Studies by Chang (2000), Chang and Bell (2002), and Igwebuike and Oriaifo (2009), in the area of cognitive achievement, present some contradictions to the result of this study but support the present study in the area of affective achievement. Specifically, Chang (2000) and Chang and Bell (2002) found that this instructional strategy improved students' perceptions of interest, satisfaction, enjoyment and achievement, willingness to attend, listen to lesson and participate in discussion; and increased learning commitment out of class.

Speculatively, two factors may account for this result. First, one of the characteristics of conceptual change pedagogy is that it provides opportunities for students, according to Taylor, Fraser and Fisher (1997), to: (i) negotiate with the teacher about the nature of their learning activities, (ii) participate in the determination of assessment criteria and undertake self-assessment and peer assessment; (iii)engage in collaborative and open-ended inquiry with fellow students; and (iv) participate in reconstructing the social norms of the classroom. A teaching/learning situation premised on participation of the students and their engagement in collaborative investigation among themselves will improve their affect. It will be more so when negotiation which, as mentioned earlier, allows them to become an integral part of classroom communication (Bauersfeld, 1991), is also a premise for organizing such a situation.

Secondly, more can be learned about the characteristics of the conceptual change pedagogy, from the revelation by West and Pines (1983) that while it is important to create situations which will challenge the students' alternative conceptions to bring about changes, their feelings and dispositions are an important aspect of the classroom process. They say that the learner should feel good, or proud, or satisfied after a conceptual change lesson but should not feel bad, demeaned, or dissatisfied. This is because, they argue, learning is feeling good, proud, satisfied and not simply motivational, attitudinal, or affective antecedents upon which it depends. They are supported, though indirectly by studies carried out by Goh and Fraser (1998), Hoffner-Moss and Fraser (2002), Margianti, Fraser, and Aldridge (2002), den Brok, Brekelmans, and Wubbels (2004), which indicate that students' perceptions of their classroom psychosocial environment have great influence on their affective outcomes, among others.

The result obtained in this study, with respect to affective outcome, is heart-warming. One of the major goals of teaching science is the development of affective components. Conceptual change pedagogy has the potency to achieve this goal, as shown in this and similar studies. Another source of joy is the strong association between affective components and cognitive achievement (Sandal, Wold, \& Bronis, 1999; Igwebuike, 2000; Igwebuike \& Oriaifo, 2009). This established association lends more credence to the potency of the pedagogy.

An implication of this result for science teaching is that science teachers, as well as science teacher educators in non-western cultures should be sensitized about the potency of conceptual change pedagogy in developing the affective sets among grade 8 level junior secondary school students. It must however, be acknowledged that such sensitization is a mere suggestion since it is not based on firm conclusion, and generalization cannot be made beyond the sample of study. The study was carried out on high ability students 
and is likely the result may be different if the study uses low ability students as sample. Another reason that may jeopardize generalizability is the absence of strict control of extraneous variable in the design employed. Consequently, there are probable effects of some confounding variables which can impair external validity. It should also be noted that this study is a single-variable (independent) study. Walberg (1970) suggests that each of the predictor variables of learning outcomes may be necessary but insufficient by itself for classroom learning to occur. Studies that will increase the number of independent variables and determine their interactive effects are therefore strongly advocated. Such studies should also provide more reasonable or strict control of extraneous variables to improve on the external validity. By implication and as mentioned earlier, cautions interpretation and application of the conclusions of this study to integrated science teaching are encouraged. Despite that, the findings of this study, at least suggest the fruitfulness and the desirability of the direction of enquiry attempted in this study, especially in the non-western cultures.

\section{References:}

Abimbola, I. O. (1988). The problem of terminology in the study of students' conceptions in science. Science Education, 72(2), 175-184. <http://dx.doi.org/10.1002/sce.3730720206>

Afemikhe, O. A. (1985). The effect of formative testing on students' achievement in secondary school mathematics. Unpublished Doctoral dissertation, University of Ibadan, Nigeria.

Asim, A. E. (1998). An evaluation of the relative effectiveness of two interactive approaches based on the constructivist perspective for teaching primary science. Unpublished Doctoral dissertation, University of Ibadan.

Ausubel, D. P. (1963). The psychology of meaningful learning. New York: Grune \& Stratton.

Bajah, S. T., \& Asim, A (2000). Constructivism and science learning: experimental evidence in a Nigerian setting. Journal of the World Council for Curriculum and Instruction, Nigeria Chapter, 3(1), 106-114.

Bauersfeld, H. (1991). The structure of structures: Development and function of mathematizing as a social practice. Unpublished mimeograph. Bickefeld: IDM der Universitat.

Bell, B. (2005). Pedagogies developed in the learning in science projects and related theses. International Journal of Science Education, 27(2), 159-182. <http://dx.doi.org/10.1080/0950069042000276703>

Benjamin, A., \& Egho, E. (2008). Constructivism: a paradigm for effective classroom practice. Agbor Journal of science education, 3(1), $265-277$.

Chang, W. (2010). Improving teaching and learning of university physics in Taiwan. Unpublished Ph.D. thesis, University of Waikato, Hamilton.

Chang, W., \& Bell, B. (2002). Making content easier or adding more challenge in year one university physics. Research in Science Education, 32(1), 81 - 96. <http://dx.doi.org/10.1023/A:1015054804515>

Cobern, W. W. (1991). World view theory and science education research, NARST Monograph No. 3 Cincinnati, OH: National Association for Research in Science Teaching.

Cobern, W. W. (1996). Constructivism and non-western science education research. International Journal of Science Education, 4(3), 287-302.

denBrok, P., Brekelmans, M., \& Wubbels, T. (2004). Interpersonal teacher behavior and student outcomes. School Effectiveness and Improvements, $15(3 \& 4), 407-422$. $<$ http://dx.doi.org/10.1080/09243450512331383262>

Driver, R., \& Oldham, V. (1986). A constructivist approach to curriculum development in science education. Studies in Science Education, 12, 105 - 122. <http://dx.doi.org/10.1080/03057268608559933>

Duit, R. (1981). Understanding energy as a conserved quantity. European Journal of Science Education, 3, 291-301. <http://dx.doi.org/10.1080/0140528810030306>

Duit, R. (1984). Learning the energy in school-empirical results from the Philippines and West Germany. Physics Education, 19, 59-66. <http://dx.doi.org/10.1088/0031-9120/19/2/306>

Gilbert, J. K., \& Watts, D. M. (1983). Concepts, misconceptions and alternative conceptions: changing perspectives of science education. Studies in Science Education, 10, 61-98. $<$ http://dx.doi.org/10.1080/03057268308559905> 
Effects of conceptual change pedagogy on achievement by high ability integrated science students

Goh, S. C., \& Fraser, B. J. (1998). Interpersonal teacher behavior, Classroom environment and student outcomes in primary mathematics in Singapore. Learning Environments Research, 1, 199 - 229. <http://dx.doi.org/10.1023/A:1009910017400>

Head, J. (1986). Research into alternative frameworks: promise and problems. Research in Science and Technological Education, 4(2), 203 - 211. <http://dx.doi.org/10.1080/0263514860040210>

Hoffner-Moss, M. C., \& Fraser, B. J. (2002). Using environment assessments in improving teaching and learning in high school biology classrooms. Paper presented at the annual meeting of the National Association for Research in Science Teaching, New Orleans.

Igwebuike, T. B. (1988). Let's watch out: conceptual ecology is not our side. Paper presented at the 29th Annual Conference of the Science Teachers' Association of Nigeria at the University of Ibadan, Nigeria, August.

Igwebuike, T. B. (2000). Effects of constructivist instructional strategy on students' achievement in integrated science. Unpublished Doctoral dissertation, University of Benin, Nigeria.

Igwebuike, T. B., \& Oriaifo S. O. (2009). Nature of classroom environment and achievement in science: a test of efficacy of constructivist instructional strategy. A research paper, College of Education, WarriNigeria.

Jegede, O. J., \& Taylor, P. C. (1998). The role of negotiation in a constructivist-oriented hand-on and minds on science laboratory classroom. Journal of the Science Teachers' Association of Nigeria, 33(1 \& 2), 88 98.

Kim, H. B., Fisher, D. L., \& Fraser, B. J. (1999). Assessment and investigation on constructivist science learning environments in Korea. Research in Science and Technological Education, 17, 239-249. http://dx.doi.org/10.1080/0263514990170209

Kirkwood, V. (1988). Energy for a change: teaching and learning about the energy concept in junior secondary school science classrooms in New Zealand. Unpublished Doctoral dissertation, University of Waikato.

Kyle, W. Jr. (1993). Rethinking science education: Knowledge, power cultural struggle, and possibility. Paper presented at the 1993 UNESCO International Conference on Science Education in Developing Countries: From Theory to Practice, Jerusalem.

Lawson, A. E., \& Thompson, I. D. (1988). Formal reasoning ability and biological misconceptions concerning genetics and natural selection. Journal of Research in Science Teaching, 25, 733 - 746. $<$ http://dx.doi.org/10.1002/tea.3660250904>

Lewin, K. (1990). International perspectives on the development of science education: food for thought. Studies in Science Education, 18, 1-23. <http://dx.doi.org/10.1080/03057269008559979>

Margianti, E. S., Fraser, B. J., \& Aldridge, J. M. (2001). Investigating the learning environment and students' outcomes at the university level in Indonesia. Paper presented at the Annual meeting of the Australian Association for Research in Education (AARE) Fremantle, Western Australia.

McCarthy, M. (1991). Negotiation in the classroom. Journal of Further and Higher Education, 15(1), 75-79. $<$ http://dx.doi.org/10.1080/0309877910150108>

Mehrens, W. A., \& Lehmann, I. J. (1975). Measurement and evaluation in education and psychology. New York: Holt, Rinehart \& Winston.

Ndioho, O. (2007). Effect of constructivist-based instructional model on senior secondary students' achievement in biology. In U. Nzewi (Ed.) Science, technology and mathematics education for sustainable development (pp. 98-101). Ibadan, Nigeria: Heinemann Educational Books.

Odhiambo, T. R. (1972). Understanding science: the impact of the African view of nature. In P. G. Gilbert, \& M. N. Lovegrove (Eds.), Science education in Africa (pp. 39-46). London, UK: Heinemann.

Ogunniyi, M. B. (1984). African traditional world-view and modern science. Working paper submitted to the International Development and Research Centre (IDRC).

Ogunniyi, M. B. (1988). Adapting western science to traditional African culture. International Journal of Science Education, 10(1), 1-9. <http://dx.doi.org/10.1080/0950069880100101>

Okebukola, P. A., \& Jegede, O. J. (1990). Eco-cultural influences upon students' concept attainment in science. Journal of Research in Science Teaching, 27(7), $661-669$. 
Igwebuike, T. B.

$<$ http://dx.doi.org/10.1002/tea.3660270706>

Osborne, R., \& Gilbert, J. (1980a). A technique for exploring students' views of the world. Physics Education, 15, 376-379. <http://dx.doi.org/10.1088/0031-9120/15/6/312>

Osborne, R., \& Gilbert, J. (1980b). A method for investigating concept understanding in science. European Journal of Science Education, 2(3), 311-321. <http://dx.doi.org/10.1080/0140528800020311>

Rowell, J., \& Dawson, C. (1985). Equilibration, conflict and instruction: a new class-oriented perspective. European Journal of Science Education, 7(4), 331-344. <http://dx.doi.org/10.1080/0140528850070401>

Samdal, O., Wold, B., \& Bronis, M. (1999). Relationship between students' perceptions of school environment, their satisfaction with school and perceived academic achievement: an international study. School Effectiveness and Improvement, 10(3), 296 - 320. <http://dx.doi.org/10.1076/sesi.10.3.296.3502>

Snively, G. (1985). Sea of images: a study of curriculum in use. Unpublished Doctoral dissertation, University of British Columbia, Vancouver, Canada.

Solomon, J. (1983a). Learning about energy: how people think in two domains. European Journal of Science Education, 5(1), 49-59. <http://dx.doi.org/10.1080/0140528830050105>

Solomon, J. (1983b). Messy, Contradictory and obstinately persistent: A study of children's out-of-school ideas about energy. School Science Review, 65, 255-263.

Strike, K., \& Posner, G. J. (1985). A conceptual change view of learning and understanding. In L. H. West \& A. L. Pines (Eds.). Cognitive structure and conceptual change (pp. 211-231). New York: Academic Press.

Taylor, P. C., Fraser, B. J., \& Fisher, D. L. (1997). Monitoring constructivist classroom learning environments. International Journal of Educational Research, 27, 293-302. <http://dx.doi.org/10.1016/S0883-0355(97)90011-2>

Trumper, R. (1990). Being constructive: an alternative approach to the teaching of energy concept, Part I. International Journal of Science Education, 12(4), 411 - 436. <http://dx.doi.org/10.1080/0950069900120402>

Trumper, R. (1991). Being constructive: an alternative approach to the teaching of energy concept Part II. International Journal of Science Education. 13(2), 142-160.

Walberg, H. J. (1970). A model for research on instruction. School Review, 78, 185-200. $<$ http://dx.doi.org/10.1086/442899>

West, L. H., \& Pines, A. L. (1983). How “rational” is rationality”? Science Education, 67(1), 37-39. $<$ http://dx.doi.org/10.1002/sce.3730670106>

Wheatley, G. H. (1991). Constructivist perspectives on science and mathematics learning. Science Education, 75(1), 9 - 21. <http://dx.doi.org/10.1002/sce.3730750103>

Zietsman, A. I., \& Hewson, P. W. (1986). Effect of instruction using micro-computer simulations and conceptual change strategy on science learning. Journal of Research in Science Teaching, 23(1), 27-39.

<http://dx.doi.org/10.1002/tea.3660230104> 